\title{
Characterisation of rice fallow period for increasing cropping intensity in Khordha district of Odisha
}

\author{
S. PATTANAYAK*, B.S. RATH, S. PASUPALAK, A.K.B. MOHAPATRA, A. BALIARSINGH, \\ A. NANDA and G.S. PANIGRAHI \\ Department of Agricultural Meteorology, Orissa University of Agriculture and Technology, \\ Bhubaneswar, Odisha, India \\ *Corresponding author: agm.ca.ouat@gmail.com
}

\begin{abstract}
The possibility of increasing the cropping intensity in Khordha district was assessed by block-wise characterisation of rainfall, soil texture, available water holding capacity of soil and district level temperature during the rice fallow period as well as deciding the appropriate sowing window for both kharif and rabi crops. More than $50 \%$ chances of occurrence of wet weeks at the beginning of the kharif season (20-22 SMW) indicated that the summer ploughing and initial seed bed preparation could be taken up during the period followed by sowing of rice from 23 SMW. The $42-43$ SMW with greater than $30 \%$ initial probability of wet week at $20 \mathrm{~mm}$ threshold limit. Considering the length of growing period (LGP) available, the adjustment of rice variety duration by 10-15 days in medium land and advancement of pulse sowing almost by 15 days before harvest of the rice crop (Pira crop) in low land was registered as the best suitable option for rabi pulses to ensure better utilisation of rice fallow. In addition to these, harvesting surplus water during kharif and storing in farm ponds for judicious utilisation during rabi season further enhanced the possibility of utilisation of rice fallow and increasing the cropping intensity. In the event of delayed monsoon the rice duration has to be adjusted accordingly not to sacrifice the designated suitable period for rabipulses
\end{abstract}

Keywords: Rice fallow, rainfall probability, effective rainfall, LGP, sowing window

Rice fallows basically refers to those medium and low lands kharif sown rice areas which remain uncropped during rabi (winter) season due to various reasons. Characterisation of rice fallow period involves studying the climatic and soil characteristics superimposed on Length of growing period (moisture availability period) and cropping system in order to bring out the agricultural potential of the concerned region. Rice is the major crop, grown over an area of more than $18 \mathrm{mha}$ in Eastern states comprising Assam, Bihar, Chhattisgarh, Jharkhand, Odisha and West Bengal. Due to various reasons such as cultivation of long duration paddy varieties, excessive and lack of moisture in rice field at the time of planting of winter crops, lack of irrigation, non availability of seeds of short duration varieties of rabi crops more specifically the short duration cold tolerant pulse varieties and other socioeconomic problems like stray cattle and blue bulls etc, an estimated area of more than $8 \mathrm{mha}$ remain fallow after harvest of paddy during rabi in these states. Odisha has a cultivated area of 61.80 lakh hectares of which 29.14, 17.55 and 15.11 lakh ha are high, medium and low land, respectively. Paddy is also the dominant crop of the state covering about 38.80 lakh hectares in kharif and 3 lakh hectares during rabi. Rice fallow is estimated to12.20 lakh hectares in the state and 30 thousand hectares in Khordha district. After rice harvest, rabi crops are grown on residual soil moisture in the rice fallow. So, a good rainfall towards the end of the kharif crop growing season provides sufficient moisture for germination and establishment of the next crop. Critical observation of the rainfall pattern of the state clearly indicated that though there was not much variation in quantum of rainfall during the recent past decade but the number of intermittent dry spells and intense rainy days has increased significantly alongwith decrease in number of total rainy days per year. Besides, the occurrence of rainfall during post-monsoon is completely uncertain. This situation necessitates the conservation of surplus rain water during kharif season and its effective utilisation during the lean period. In this context 12.20 lakh hectares of rice fallow is the most suitable area for increasing the production to meet the demands of growing population. Inclusion of short duration low water requiring pulses (green gram/ blackgram/ gram) offered excellent opportunity to utilize carry-over residual soil moisture in rice fallow (Rahmiaanna et al., 2000; Kar et al., 2004). 
Table 1: Block-wise soil texture, soil type and AWHC of Khordha district

\begin{tabular}{llrrrrr}
\hline Sl. No. & Blocks & Sand $\%$ & Silt $\%$ & Clay $\%$ & Soil Type & AWHC (mm) \\
\hline 1. & Balianta & 73.7 & 9.3 & 17.0 & Sandy loam & 128 \\
2. & Balipatna & 74.1 & 12.0 & 13.9 & Loamy sand & 135 \\
3. & Banapur & 61.2 & 18.7 & 20.1 & Sandy clay loam & 145 \\
4. & Begunia & 80.8 & 6.5 & 12.7 & Loamy sand & 126 \\
5. & Bhubaneswar & 85.8 & 5.2 & 9.0 & Sandy & 106 \\
6. & Bolagarh & 79.4 & 7.8 & 12.8 & Loamy sand & 128 \\
7. & Chilika & 65.4 & 14.5 & 20.1 & Sandy clay loam & 137 \\
8. & Jatani & 81.5 & 8.3 & 10.2 & Loamy sand & 110 \\
9. & Khordha & 77.2 & 10.0 & 12.8 & Loamy sand & 112 \\
10. & Tangi & 77.5 & 9.8 & 12.7 & Sandy & 112 \\
\hline
\end{tabular}

\section{MATERIALS AND METHODS}

The study was conducted for Khordha district of Odisha which lies between $19^{\circ} 55^{\prime}-20^{\circ} 25^{\prime} \mathrm{N}$ Latitude and $84^{\circ} 55^{\prime}-86^{\circ} 5^{\prime} \mathrm{E}$ Longitude on pilot basis for possible utilisation of rice fallow. Khordha has average rainfall of $1408 \mathrm{~mm}$ (1993-2017) with maximum and minimum temperature of 42.2 and $11.1{ }^{\circ} \mathrm{C}$, respectively. The district comprises of 10 blocks namely Balianta, Balipatna, Banapur, Begunia, Bhubaneswar, Bolagarh, Chilika, Jatani, Khordha \& Tangi. All the weather data including maximum temperature $\left(\mathrm{T}_{\max }\right)$, minimum temperature $\left(\mathrm{T}_{\min }\right)$, and evaporation $(\mathrm{E})$ has been collected from the Department of Agricultural Meteorology, OUAT, Bhubaneswar for the period 1993-2017 (25 years). Block wise rainfall data of Khordha district has been obtained from SRC site of Govt. of Odisha for the same period.

\section{Probability analysis of rainfall}

Incomplete gamma distribution model has been used to determine the amount of rainfall at three different probability levels (90\%, 75\%, and 50\%). Markov Chain probability model has been used for calculating the initial and conditional probability of dry spells using weekly rainfall data. Rainfall probability of the district was estimated by averaging the values of all the blocks. Twenty mm of rainfall per week is adequate for all the growth stages of crops. So, it has been taken as the threshold limit (Ramdurg et al., 2015) for designating a week as dry or wet and have calculated respective probability by Markov Chain Model procedure (Pandarinath, 1991; Kar et al., 2014; Vijaya Kumar et al., 2019).

\section{Soil analysis}

Soil physical properties of the ten blocks of Khordha district were characterised on the basis of their soil texture using 'Bouyoucos Hydrometer' method and soil type was decided using soil textural triangle. The available water holding capacity of the soil was calculated using pedo- transfer function Table 1.

\section{Length of growing period (LGP)}

LGP is considered as the period with sufficient soil moisture storage which can support any crop growth that includes the period from onset to cessation of rainfall during rainy season, the post monsoon rainfall and the available water holding capacity (AWHC) of the soil. Based on the formula given by Sattar et al., (2013) the length of growing period was calculated. It was calculated for 10 different blocks of the district using the following formula:

\section{LGP $=$ Duration of rainy season in days $+[$ \{Post monsoon rainfall $(\mathrm{mm})+$ AWHC $(\mathrm{mm})\} /$ average evaporative demand of atmosphere during post monsoon period]}

Forward and backward accumulation methods as suggested by Dash and Senapati (1992)were used for calculating mean onset and cessation of rainy season.

\section{Deciding of sowing window for kharif and rabi crops}

The sowing window for kharif and rabi crops have been decided by using the initial and conditional probability analysis of rainfall during monsoon period using Markov chain model and considering the LGP that has been estimated using the formula given by Sattar et al., (2013). The initial 
Table 2: Annual and weekly rainfall probability of Khordha district

\begin{tabular}{|c|c|c|c|c|}
\hline \multirow{2}{*}{ Week } & \multicolumn{3}{|c|}{ Probability levels } & \multirow{2}{*}{$\operatorname{Mean}(\mathrm{mm})$} \\
\hline & $90 \%$ & $75 \%$ & $50 \%$ & \\
\hline$\overline{19}$ & 0.6 & 3.6 & 14.5 & 28.7 \\
\hline 20 & 0.8 & 3.5 & 12.3 & 21.7 \\
\hline 21 & 1.1 & 4.4 & 14.2 & 24.1 \\
\hline 22 & 1.1 & 3.3 & 8.8 & 12.6 \\
\hline 23 & 3.5 & 8.3 & 18.2 & 237. \\
\hline 24 & 4.5 & 13 & 32.9 & 47.9 \\
\hline 25 & 9.9 & 20.3 & 39.3 & 48.5 \\
\hline 26 & 17.2 & 29.1 & 47.9 & 54.4 \\
\hline 27 & 14 & 30.2 & 60.5 & 77.1 \\
\hline 28 & 7 & 19.3 & 46.8 & 66.9 \\
\hline 29 & 25.8 & 41.3 & 65 & 72.5 \\
\hline 30 & 23 & 36.2 & 56.4 & 62.4 \\
\hline 31 & 28.7 & 46.7 & 74.6 & 84 \\
\hline 32 & 17.5 & 31.3 & 54.1 & 63.1 \\
\hline 33 & 21.6 & 39.4 & 69.3 & 81.9 \\
\hline 34 & 22.3 & 36.3 & 57.9 & 64.9 \\
\hline 35 & 9.3 & 47.6 & 76.1 & 85.6 \\
\hline 36 & 22.5 & 35.7 & 55.7 & 61.7 \\
\hline 37 & 13 & 24.6 & 44.5 & 53.1 \\
\hline 38 & 25.8 & 41.5 & 65.7 & 73.5 \\
\hline 39 & 6.2 & 15.2 & 33.5 & 44.9 \\
\hline 40 & 6.8 & 17.5 & 40.4 & 55.8 \\
\hline 41 & 1.5 & 6.7 & 22.7 & 40.1 \\
\hline 42 & 1.3 & 5.7 & 19.8 & 35.5 \\
\hline 43 & 0.3 & 2.2 & 11.9 & 28.7 \\
\hline 44 & 0.2 & 1.9 & 10.4 & 25.1 \\
\hline 45 & 0.2 & 1.4 & 6 & 11.9 \\
\hline Annual & 1092.6 & 1238.7 & 1415.9 & 1432.6 \\
\hline
\end{tabular}

probability of wet weeks should be more than $50 \%$ for sowing of kharif rice and more than $30 \%$ for sowing of rabi crop in rainfed areas (Ray et al., 2018).

\section{Effective rainfall}

Estimation of effective rainfall will give us the idea for surplus water available for run off. The monthly effective
Table 3: Block-wise monsoon and post monsoon rainfall ( $\mathrm{mm})$ of Khordha district at three probability level

\begin{tabular}{|c|c|c|c|}
\hline \multicolumn{4}{|c|}{ Monsoon rainfall (mm) } \\
\hline Block & $50 \%$ & $75 \%$ & $90 \%$ \\
\hline Balianta & 949.9 & 434.7 & 191.3 \\
\hline Balipatna & 657.4 & 289 & 120 \\
\hline Banapur & 815.4 & 372 & 165.2 \\
\hline Begunia & 766.5 & 323.6 & 129.9 \\
\hline Bhubaneswar & 999.7 & 467.9 & 208.7 \\
\hline Bolagarh & 716.5 & 304 & 121.3 \\
\hline Chilika & 828.8 & 331.8 & 166.4 \\
\hline Jatani & 966.6 & 435.2 & 210.2 \\
\hline Khordha & 870.1 & 393.2 & 167.3 \\
\hline Tangi & 878.5 & 413.9 & 185.9 \\
\hline \multicolumn{4}{|c|}{ Post monsoon rainfall (mm) } \\
\hline Balianta & 61.3 & 14.4 & 4.8 \\
\hline Balipatna & 5.8 & 13.8 & 4.7 \\
\hline Banapur & 64.5 & 15.6 & 4.2 \\
\hline Begunia & 51.5 & 13.6 & 4.2 \\
\hline Bhubaneswar & 65.1 & 16.1 & 4.2 \\
\hline Bolagarh & 53.5 & 12.4 & 3.1 \\
\hline Chilika & 65.2 & 16.3 & 4.3 \\
\hline Jatani & 63.2 & 16.1 & 4.1 \\
\hline Khordha & 57 & 13.9 & 3.7 \\
\hline Tangi & 63.7 & 16.2 & 4.4 \\
\hline
\end{tabular}

rainfall was calculated following USDA Soil Conservation Service method Sharma et al., (2010).

$\mathrm{P}_{\mathrm{e}}=\mathrm{P}_{\mathrm{t}} / 125\left(125-0.2 \mathrm{P}_{\mathrm{t}}\right)\left(\right.$ when $\left.\mathrm{P}_{\mathrm{t}}<250 \mathrm{~mm}\right)$

$\mathrm{P}_{\mathrm{e}}=125+0.1 \mathrm{P}_{\mathrm{t}}\left(\right.$ when $\left.\mathrm{P}_{\mathrm{t}}>250 \mathrm{~mm}\right)$

Where, $\mathrm{P}_{\mathrm{e}}=$ monthly effective rainfall $(\mathrm{mm})$ and $\mathrm{P}_{\mathrm{t}}=$ total monthly rainfall $(\mathrm{mm})$.

\section{RESULTS AND DISCUSSION}

\section{Probability analysis of rainfall}

The expected amount of annual rainfall for the district (average of all the blocks) at 90\%, 75\% and 50\% are 1092.6 $\mathrm{mm}, 1238.7 \mathrm{~mm}$ and $1415.9 \mathrm{~mm}$, respectively (Table 2). After the onset of monsoon, i.e. from 23 SMW till 40 SMW the rainfall amount is very high at $75 \%$ probability level which is 
Table 4: Block-wise length of growing period (LGP) of Khordha district

\begin{tabular}{lccccr}
\hline Blocks & $\begin{array}{c}\text { SW Monsoon } \\
\text { Period (days) }\end{array}$ & $\begin{array}{c}\text { Post monsoon } \\
\text { rainfall (mm) } \\
\text { (cessation of } \\
\text { monsoon-Jan) }\end{array}$ & $\begin{array}{c}\text { AWHC } \\
(\mathrm{mm})\end{array}$ & $\begin{array}{c}\text { Average evaporation } \\
\text { during post monsoon } \\
\text { period (mm/day) }\end{array}$ & LGP (days) \\
\hline Balianta & 120 & 154.9 & 128 & 3.5 & 3.5 \\
Balipatna & 117 & 109.4 & 135 & 3.5 & 187 \\
Banapur & 118 & 134.2 & 145 & 3.5 & 198 \\
Begunia & 120 & 99.3 & 126 & 3.5 & 184 \\
Bhubaneswar & 122 & 132.9 & 106 & 3.5 & 180 \\
Bolagarh & 118 & 118.6 & 128 & 3.5 & 204 \\
Chilika & 117 & 141.7 & 137 & 3.5 & 190 \\
Jatani & 121 & 129.9 & 110 & 3.5 & 186 \\
Khordha & 121 & 114.5 & 112 & 3.5 & $\mathbf{3 0 6}$ \\
Tangi & 118 & 136.7 & 112 & $\mathbf{3 . 5}$ & 189 \\
District & $\mathbf{1 2 1}$ & $\mathbf{1 3 8 . 9}$ & $\mathbf{1 2 4}$ & & $\mathbf{1 9 6}$ \\
\hline
\end{tabular}

Table 5: Block-wise rice fallow period characterization of Khordha district

\begin{tabular}{|c|c|c|c|c|c|}
\hline Blocks & $\begin{array}{r}\text { Period } \\
(\mathrm{SMW})\end{array}$ & $\begin{array}{r}\text { Amount of } \\
\text { rainfall (mm) }\end{array}$ & $\begin{array}{l}\text { Initial Probability } \\
\text { of wet weeks (\%) }\end{array}$ & $\begin{array}{r}\text { Conditional } \\
\text { Probability of } \\
\text { wet/wet weeks }(\%)\end{array}$ & $\begin{array}{r}\text { LGP available } \\
\text { for rabi crop } \\
\text { (days) }\end{array}$ \\
\hline Balianta & 43 & 37.0 & 32 & 55 & 72 \\
\hline Balipatna & 42 & 28.1 & 36 & 67 & 68 \\
\hline Banapur & 42 & 42.7 & 44 & 64 & 79 \\
\hline Begunia & 42 & 27.9 & 40 & 45 & 63 \\
\hline Bhubaneswar & 42 & 40.1 & 36 & 55 & 67 \\
\hline Bolagarh & 42 & 29.4 & 32 & 58 & 70 \\
\hline Chilika & 42 & 40.0 & 44 & 67 & 85 \\
\hline Jatani & 42 & 32.4 & 48 & 50 & 68 \\
\hline Khordha & 42 & 29.2 & 36 & 50 & 64 \\
\hline Tangi & 43 & 36.3 & 30 & 50 & 62 \\
\hline
\end{tabular}

the most suitable period for growing of kharif rice. The amount of rainfall again decreases gradually after 40 SMW (during cessation of monsoon) and so water stress condition prevails during that period for rabi season crops. Available water holding capacity of soil satisfies the water requirement of the pulses.

Among the blocks of the district, Bhubaneswar block received highest amount of dependable rainfall (467.9 mm) during monsoon period and Balipatna block received lowest (289 mm) amount of rainfall (Table 3), whereas, during post monsoon period Chilika received maximum rainfall (16.3 $\mathrm{mm}$ ) and Bolagarh received the least (12.4 mm)(Table 3). The analysis indicated that good amount of residual soil moisture is required for the blocks receiving less amount of rainfall for growing of rabi pulses.

\section{Length of growing period}

The growing period starts with the beginning of monsoon. The soil type plays an important role on the variability of sowing of crops due to its water holding capacity with the difference in depth. The growing season determines the period that the land can be utilised and accordingly the crops and or varieties can be selected for judicious utilisation 
Table 6: Block wise sowing window for kharif and rabi crops

\begin{tabular}{|c|c|c|c|c|c|c|}
\hline \multirow{2}{*}{ Blocks } & \multirow{2}{*}{$\begin{array}{l}\text { LGP } \\
\text { (days) }\end{array}$} & \multirow{2}{*}{$\begin{array}{c}\text { Sowing } \\
\text { window for } \\
\text { kharif rice } \\
\text { (SMW) }\end{array}$} & \multicolumn{2}{|c|}{$\begin{array}{l}\text { Duration of rice crop } \\
\text { (days) }\end{array}$} & \multirow{2}{*}{$\begin{array}{r}\text { Sowing } \\
\text { window for } \\
\text { rabi crops } \\
(\mathrm{SMW})\end{array}$} & \multirow{2}{*}{ Rabi crops } \\
\hline & & & $\begin{array}{l}\text { Medium } \\
\text { land }\end{array}$ & $\begin{array}{l}\text { Low } \\
\text { land }\end{array}$ & & \\
\hline Balianta & 201 & 24 & 135 & 150 & $42-43$ & \multirow{7}{*}{$\begin{array}{l}\text { Black gram/ Green gram/ } \\
\text { Horse gram/ Lathyrus as sole } \\
\text { or paira crop under residual } \\
\text { soil moisture condition. } \\
\text { Linseed and chickpea may be } \\
\text { new introduction in the area } \\
\text { with high soil moisture storage } \\
\text { of almost } 150 \mathrm{~mm}\end{array}$} \\
\hline Balipatna & 187 & 24 & 120 & 145 & 42 & \\
\hline Begunia & 184 & 24 & 120 & 145 & 42 & \\
\hline Bhubaneswar & 196 & 23 & 120 & 150 & 42 & \\
\hline Bolagarh & 189 & 24 & 120 & 150 & 42 & \\
\hline Khordha & 192 & 24 & 135 & 145 & $42-43$ & \\
\hline Tangi & 195 & 24 & 135 & 145 & $42-43$ & \\
\hline
\end{tabular}

Table 7: Block wise effective rainfall of Khordha district

\begin{tabular}{|c|c|c|c|c|c|}
\hline Blocks & $\begin{array}{r}\text { Annual } \\
\text { Rainfall (mm) }\end{array}$ & $\begin{array}{r}\text { Effective } \\
\text { Rainfall (mm) }\end{array}$ & Contribution (\%) & $\begin{array}{r}\text { Amount of water } \\
\text { lost (mm) }\end{array}$ & Contribution (\%) \\
\hline Balianta & 1607.5 & 913.7 & 50 & 693.7 & 43.0 \\
\hline Balipatna & 1110.9 & 769.1 & 69.2 & 341.7 & 30.8 \\
\hline Banapur & 1423.0 & 902.7 & 63.4 & 520.2 & 36.6 \\
\hline Begunia & 1335.9 & 849.4 & 63.6 & 486.4 & 36.4 \\
\hline Bhubaneswar & 1655.2 & 943.9 & 50 & 711.2 & 43.0 \\
\hline Bolagarh & 1240.4 & 815.5 & 65.7 & 424.8 & 34.3 \\
\hline Chilika & 1445.3 & 894.4 & 61.9 & 550.8 & 38.1 \\
\hline Jatani & 1624.7 & 940.9 & 57.9 & 683.7 & 42.1 \\
\hline Khordha & 1429.7 & 868.1 & 60.7 & 561.6 & 39.3 \\
\hline Tangi & 1452.2 & 900.8 & 60 & 551.3 & 38.0 \\
\hline District & 1532.8 & 936.2 & 61.1 & 596.5 & 38.9 \\
\hline
\end{tabular}

of land. The LGP of different blocks has been mentioned in Table 4.

The total length of growing period in a year has been calculated for all the ten blocks by using LGP formula used by Sattar et al., (2013). The total average number of LGP for Khordha district is 196 days (Table 4). Chilika has the highest number of LGP (204 days) and Begunia has the lowest number of LGP(184 days).

\section{Characterisation of rice fallow period}

Characterisation of the fallow land immediately following the rice crop is important for utilising it with rabi crops. Both medium and low lands are suitable for growing rabi season crops instead of keeping the field fallow after rice. In medium lands farmers mostly grow medium duration (120135 days) variety and in low lands mid late varieties (145-150 days) during kharif. 
Initial probability of wet weeks for sowing of rabi crops should be $>30 \%$ and conditional probability of wet weeks followed by wet weeks should be average $(>50 \%)$ which is available during 42-43 SMW in all the blocks excepting the Begunia block where the conditional probability is $<50 \%$ (45 $\%)$. The days available with proper soil moisture for production of rabi crops is highest in Chilika ( 85 days) block whereas lowest in Begunia block with 63 days (Table 5).

\section{Deciding of sowing window}

Deciding of sowing window for kharif rice depends on the initial and conditional probability of rainfall during the monsoon period. Chances of occurrence of wet week more than $50 \%$ at the beginning of Kharif season indicates that summer ploughing and initial seed bed preparations shall be taken up in the 20-22 SMW and sowing operations can be taken up since 23 SMW. Similarly, for rabi pulses 42-43 SMW has been found suitable for sowing as the initial probability of wet weeks is more than $30 \%$ and the conditional probability of wet week followed by wet week is average (around $50 \%$ ). The optimum temperature required for sowing of pulses is also available in these weeks. Available LGP for rabi crops is also sufficient to grow a pulse crop successfully without any water stress.

Depending upon the LGP available for cropping in different blocks of Khordha district rice varieties of specific duration have been selected for medium and low lands. Mostly rice varieties of 120-135 days were selected for medium lands and of 145-155 days for low lands to accommodate the rabi crop after harvesting of rice in medium land and before harvesting as Paira crop mostly in low lands (Table 6).

\section{Effective rainfall}

Total annual effective rainfall (ER) of Khordha district is $936.2 \mathrm{~mm}$ which is 61 percent of the total annual rainfall (Table 7). Therefore, almost $39 \%$ of rainfall water is lost in the form of surface runoff, deep percolation and evaporation which necessitates the kind attention for reducing the losses and strategies for conservation of rain water.

Balipatna block has the highest annual effective rainfall $(69.2 \%)$ than any other blocks whereas Balianta and Bhubaneswar have the lowest utilisation of rain water annually (57\% each). Excess of water which is lost in the form of runoff, seepage and percolation needs to be harvested in water storage structures for utilisation of water during water stress conditions. Harvesting and storing of rain water in lined farm pond and other water harvesting structures are strategic approach for conservation of rain water. Judicious utilisation of this stored water can not only take care of the kharif crop during the intermittent dry spells but also increase the possibility of taking second crop. Almost 57-69\% of the total annual rainfall in all the blocks of Khordha district of Odisha is effective and rest is simply go as waste through run off and deep percolation. It is suggested to save at least $10-20 \%$ of rain water which comes to the tune of 70 to $140 \mathrm{~mm}$ by which the availability of water to rabi crop can be increased by at least 15 to 30 days so that a rabi crop can be grown successfully without water stress. Thus, the cropping intensity of different blocks can be increased remarkably and the productivity of rabi crop can also be enhanced.

\section{CONCLUSION}

Characterisation of rice fallow period is highly essential to have judicious utilisation of rice fallow by growing suitable short duration rabi crops for increasing the cropping intensity and production. The characterisation clearly illustrates that the sowing window for kharif crop is almost in 24-25 SMW and that of rabi crops is in 42-43 SMW as determined from the initial probability of wet weeks. Depending upon the LGP available, the rice variety has to be chosen based on its duration. Further, the type of rabi crops and its methods of establishment (normal sowing/ Paira cropping) has to be decided either to advance the rabi crop sowing or to sow in the standing rice crop for better utilisation of residual soil moisture. The productivity enhancement of rabi crops can also be ensured by effective harvesting of rainwater and its judicious utilisation by providing only supplemental irrigation at critical growth stages of the crop.

\section{REFERENCES}

Dash, M.K. and Senapati, P.C. (1992). Forecasting of dry and wet spell at Bhubaneswar for agricultural planning. Ind. J. Soil Conserv., 20 (1-2): 75-82.

Kar, G., Singh, R. and Verma, H.N. (2004). Productive and profitable management of rainfed lowland rice through intensive cropping and efficient water use, WTCER Bhubaneswar Res. Bull., 56.

Kar, S.K., Sahoo, D.P. and Subudhi, C.R. (2014). Weekly rainfall analysis for crop planningusing Markov's Chain model for Kandhamal district of Odisha, India. Int. J. Engg. Res. Appl., 4 (9): 139-145.

Pandarinath, N. (1991). Markov chain model probability of dry, wet weeks during monsoon period over Andhra Pradesh, Mausam, 42:393-400. 
Rahmiaanna, A.A., Adisarwanto, T., Kirchho, G., and So, H.B. (2000). Crop establishment of legumes in rainfed lowland rice based cropping systems. Soil. Til. Res., 56 (1-2): 67-82.

Ramdurg, H., Reddy, G.V.S., Krishnamurthy, D., Babu, B.H. and Nemichandrappa, M. (2015). Weekly rainfall variability and probability analysis for resource planning at Hadagali, Karnataka. Int. J. Agr. Engg., 8(2): 255-260.

Ray, M., Biswasi, S., Sahoo, K.C. and Patro, H. (2018). A Markov chain approach for wet and dry spell and probability analysis. Int. J. Curr. Microbiol. Appl. Sc., 6: 1005-1013.
Sattar, A., Kumar, M., Bobade, P. and Chandrawanshi, S. (2013). Assesing the length of growing season and drought indices in Bihar. J. Agrometeorol., 15 (Spl. Issue I): 192-194.

Sharma, B.R., Rao, K.V., Vittal, K.P.R., Ramkrishna, Y.S. and Amarsinghe, U. (2010). Estimating the potential of rain fed agriculture in India: Prospects of water productivity improvement. Agr. Water Manage., 97 (1): 23-30.

Vijaya Kumar, P., Sandeep, V.M., Bal, S.K., Sandeep, S.K. Bal, AVM Subba Rao, V.P. Pramod (2019). Spatial and temporal variability of dry spells over India. ICAR Central Research Institute for Dryland Agriculture, Hyderabad 500059, 44pp. 